\title{
Detection of VIM-1, VIM-2 and IMP-1 metallo- $\beta$-lactamase genes in Klebsiella pneumoniae isolated from clinical samples in Sanandaj, Kurdistan, west of Iran
}

\author{
Nasrin Bahmani* \\ Zoonoses Research Center, Research Institute for Health Development, Kurdistan University of Medical \\ Sciences, Sanandaj, Iran
}

Received: January 2019, Accepted: May 2019

\begin{abstract}
Background and Objectives: Klebsiella pneumoniae is an important cause of serious nosocomial infections among Gram-negative bacteria. The aim of this study was evaluating the prevalence of VIM-1, VIM-2, and IMP-1 metallo- $\beta$-lactamase genes in clinical specimens at two teaching hospitals in Sanandaj, Kurdistan west of Iran.

Materials and Methods: Four hundred different clinical specimens were collected from hospitalized patients or referred to hospitals from May 2013 to March 2014 in Sanandaj, Kurdistan, Iran. MBLs - producing K. pneumoniae detected by Double Disk Synergy Test. The MBL positive isolates were examined for the presence of VIM-1, VIM-2 and IMP-1 genes using PCR technique.

Results: Of four hundred clinical specimens, $114 \mathrm{~K}$. pneumoniae isolates were identified. Twenty-eight $(24.6 \%)$ isolates were resistant to imipenem and 15 strains (53.6\%) were positive for MBL enzymes production. PCR results showed VIM-1 and IMP-1 genes frequencies are 4 (26.7\%) and 1 (6.7\%). Only one strain of K. pneumoniae was found to be MBL producer among the outpatients.

Conclusion: The study results exhibited a high level of resistance to most of the antibiotics tested and high prevalence of MBLs producing in K. pneumoniae at two hospitals. Thus, the infection control methods and the implementation of antibiotic agents should be taken into account.
\end{abstract}

Keywords: Klebsiella pneumoniae; Carbapenem-resistant; bla $\underset{\mathrm{VIM}}{\text {; }} \mathrm{bla}_{\mathrm{IMP}}$

${ }^{*}$ Corresponding author: Nasrin Bahmani, Ph.D, Zoonoses Research Center, Research Institute for Health Development, Kurdistan University of Medical Sciences, Sanandaj, Iran.

Tel: +98-9188722650

Fax: 08733664645

Email: nasrinbahmani3@gmail.com

\section{INTRODUCTION}

Klebsiella pneumoniae is a Gram-negative bacillus belonging to the Enterobacteriaceae family, which is the major cause of nosocomial and opportunistic infections namely pneumonia, urinary tract infections, bacteremia, and wound infections across the world, with significant morbidity and mortality 
rates (1). High prevalence of antibiotic resistance in Enterobacteriaceae, especially in $K$. pneumoni$a e$ has been reported in Iran which is challenging for hospitals. The carbapenems such as imipenem, meropenem are used to treat infections caused by Gram-negative bacteria when there is resistance to other antibacterial agents. The presence of carbapenem-resistance in Gram-negative bacteria in both the community constitutes and hospital environments are a prominent development in the field of infectious disease management and control (2).

One of the most important ways to become resistant to imipenem is production of metallo-beta-lactamases (MBL). These enzymes belong to group 3 of Bush classification based on their substrate and inhibitor profiles and to Ambler class B beta-lactamases according to their amino acid sequence homology $(3,4)$. Several types of MBL have been identified in Gram-negative bacteria, which are geographically widespread including Verona integron-encoded metallo- $\beta$-lactamase (VIM), New Delhi metallo- $\beta$-lactamase (NDM) and imipenemase (IMP). The first reports on MBLs were VIM-1 in Italy and IMP-1 in Japan (5). During the last few years incidence rates of MBL production of the members of Gram-negative organisms especially, Acinetobacter baumannii, Pseudomonas aeruginosa and Enterobacteriaceae (mainly E. coli and K. pneumoniae) has been significantly increased and are the cause of life-threatening infections among human (6). Recently, there are several reports on the emergence of VIM-producing $K$. pneumoniae (VPKP) isolates across the world. VIM types (e.g. VIMI,VIM2) MBLs in Southern Europe and the Far East, Australia, North and South America, India and Iran, and IMP-type MBLs in Southeast Asia are predominant (7). There are several phenotypic methods for detection of MBL-producing bacteria. The ability of inhibitors (EDTA, Thiol compounds, and Dipicolinic acid) to control the activity of these enzymes are the foundation of these methods such as double-disk synergy test (DDST) using EDTA with IPM or ceftazidime (CAZ) (8), the Hodge test (9) and the MBL E-test (10). For identification of Gram-negative bacteria MBLs, PCR assay was described in 1996 (11).

Thus, the knowledge about the antimicrobial susceptibility patterns and MBLs-producing K. pneumoniae is helpful for the treatment of infections caused by these strains. The purpose of this study was to determine the prevalence of VIM-1, VIM-2 and IMP-1 genes of MBLs-producing in K. pneumoniae isolates in hospitalized patients or referred to Hospitals in Sanandaj, Kurdistan west of Iran.

\section{MATERIALS AND METHODS}

Bacterial isolates and identification. In this study, four hundred clinical isolates which were collected from different clinical specimens in hospitalized patients or referred (outpatients) to Beasat and Toohid hospitals during May 2013 to March 2014 in Sanandaj, Kurdistan, Iran. The included samples were as urine $(n=208)$, wound $(n=52)$, blood $(n=50)$, tracheal aspiration $(n=48)$ and sputum $(n=42)$. The isolated bacteria were identified according to standard methods including colonial morphology, Gram staining, catalase, oxidase, urease and IMVIC tests (12). Detection and final approval of testing bacterial isolates was based on the use of API20E kit (BioMerieux, Marcy-l'Etoile, France).

Antibacterial susceptibility testing. Antibacterial susceptibility testing was performed using the disk diffusion method according to the guidelines of the Clinical and Laboratory Standards Institute (CLSI) documents (13). The antibiotics used comprised of piperacillin $(100 \mu \mathrm{g})$, ceftazidime $(30 \mu \mathrm{g})$, cefotaxime $(30 \mu \mathrm{g})$, cefazoline $(30 \mu \mathrm{g})$, tetracycline $(30 \mu \mathrm{g})$, kanamycin $(30 \mu \mathrm{g})$, Imipenem $(10 \mu \mathrm{g})$, and Meropenem $(10 \mu \mathrm{g})$ (Himedia, Mombay, India). Minimum inhibitory concentration (MIC) for imipenem was determined by E-test method (AB Biodisk, Solna, Sweden) for all K. pneumoniae isolates according to CLSI guideline (14).

Detection of MBLs. The presence of MBL production was screened by the double-disk synergy test (DDST) using imipenem (IPM) disk and imipenem in combination with EDTA (6). After overnight incubation, the difference in $\geq 7 \mathrm{~mm}$ between the inhibition zone diameter of the IPM-EDTA disk and IPM the only disk was considered to be a positive for the presence of MBLs interpreted as being DDS test. In this study, K. pneumoniae ATCC 700603 was used as positive control.

Molecular identification of bla $a_{\mathrm{vIM1}}$, bla $_{\mathrm{VIM} 2}$, $\boldsymbol{b l a}_{\text {IMP1 }}$ genes. DNA was extracted using boiling method (15). Briefly, $0.5 \mathrm{ml}$ of distilled water with 1 
loop of bacteria was removed from an overnight culture (Trypticase soy agar, Merck, Germany) and the cell suspension was heated for $15 \mathrm{~min}$ at $100^{\circ} \mathrm{C}$, and then centrifuged at $13,000 \mathrm{~g}$ for $5 \mathrm{~min}$. The supernatant obtained was used as template for amplification. Polymerase chain reaction (PCR) for the detection of $b l a_{\mathrm{IMP}-1}, b l a_{\mathrm{VIM}-1}$, and $b l a_{\mathrm{VIM}-2}$ genes was carried out on a thermal cycler (Bio-Rad, USA) (16). PCR products were electrophoresed on $1.5 \%$ agarose gel and photographed by UV trans-illuminator. Primers and conditions of polymerase chain reaction are shown in Table 1.

\section{RESULTS}

This cross-sectional study was performed on four hundred clinical samples collected from hospitalized patients and outpatients in Toohid and Beasat hospitals in Sanandaj, Kurdistan, Iran. From four hundred clinical samples, 190 E. coli, 114 K. pneumoniae, 64 P. aeroginosa, 20 Enterobacter spp, 10 Proteus spp, and 2 Klebsiella oxytoca were identified. From 114 K. pneumoniae isolates (28.5\%), 77 isolates (67.5\%) belong to patients who were hospitalized and 37 $(32.5 \%)$ isolates belonged to outpatients. The distribution of $K$. pneumoniae in hospitalized patients pertaining to the type of wards shown in Table 2 . The frequency of $K$. pneumoniae isolates in outpatients included; urine 25 (67.6\%), wound 9 (24.3\%) and sputum $3(8.1 \%)$. The most and the least number of $K$. pneumoniae isolates belonged to ICU (28.9\%) and CCU (5.3\%), respectively. The study population included 54\% male and $46 \%$ female patients with an age range between 2 and 80 years. Among $114 \mathrm{~K}$. pneumoniae isolates, 28 (24.6\%) and 18 (15.9\%) were resistant to imipenem and meropenem, respectively. Resistant to kanamycin was detected among $61.4 \%$ of isolate in disk diffusion method (Fig. 1). K. pneumoniae resistant to antibacterial agents in hospitalized patients and outpatients are shown in Table 3 .

Upon examining the frequency of MBL enzymes pertaining to K. pneumoniae isolates, 28 of 114 isolates $(24.6 \%)$ were resistant to imipenem and 15 cases (53.6\%) were positive by Double Disk Synergy Test (imipenem disk alone and imipenem with- EDTA). MIC (E-test) by IPM strips was performed for all isolates. All VIM-1 and IMP-1 producing isolates of $K$. pneumoniae had MIC $>4 \mu \mathrm{g} / \mathrm{ml}$. The VIM1 produces were resistant to 4 antibiotics, cefotaxime, cefazoline, ceftazidime, and kanamycin. PCR results showed 4 isolates $(26.7 \%)$ were positive for $b l a_{\mathrm{VIM}-1}$ (Fig. 2) and 1 isolate (6.7\%) were positive for $b_{b l a}{ }_{\mathrm{IMP}-1}$ (Fig. 3), none of tested isolates were positive

Table 1. Primers and conditions of polymerase chain reaction in K. pneumoniae

\begin{tabular}{|c|c|c|c|c|c|c|}
\hline $\begin{array}{l}\text { Primer } \\
\text { Name }\end{array}$ & Primer Sequence (5' to 3') & Cycle & $\begin{array}{l}\text { Initial } \\
\text { Denaturati }\end{array}$ & Cycling & $\begin{array}{l}\text { Final } \\
\text { Extension }\end{array}$ & $\begin{array}{l}\text { Length } \\
\text { (bp) }\end{array}$ \\
\hline$\overline{\mathrm{IMP}}-1$ & $\begin{array}{l}\text { F: ACCGCAGCAGAGTCTTTGCC } \\
\text { R: ACAACCAGTTTTGCCTTACC }\end{array}$ & 33 & $94^{\circ} \mathrm{C} 5 \mathrm{~min}$ & $94^{\circ} \mathrm{C} 30 \mathrm{~s}, 56^{\circ} \mathrm{C} 30 \mathrm{~s}, 72^{\circ} \mathrm{C} 1 \mathrm{~min}$ & $72^{\circ} \mathrm{C}, 7 \mathrm{~min}$ & 587 bp \\
\hline VIM & $\begin{array}{l}\text { F: CAAGTCCGTTAGCCCATTCC } \\
\text { R: GGCACAACCACCGTATAGCAC }\end{array}$ & 33 & $94^{\circ} \mathrm{C} 5 \mathrm{~min}$ & $94^{\circ} \mathrm{C} 30 \mathrm{~s}, 57^{\circ} \mathrm{C} 30 \mathrm{~s}, 72^{\circ} \mathrm{C} 1 \mathrm{~min}$ & $72^{\circ} \mathrm{C}, 10 \mathrm{~min}$ & 539 bp \\
\hline VIM2 & $\begin{array}{l}\text { F: ATTGGTCTATTTGACCGCGTC } \\
\text { R: TGCTACTCAACGACTGAGCG }\end{array}$ & 33 & $94^{\circ} \mathrm{C} 5 \mathrm{~min}$ & $94^{\circ} \mathrm{C} 30 \mathrm{~s}, 56^{\circ} \mathrm{C} 30 \mathrm{~s}, 72^{\circ} \mathrm{C} 1 \mathrm{~min}$ & $72^{\circ} \mathrm{C}, 10 \mathrm{~min}$ & 780 bp \\
\hline
\end{tabular}

Table 2. Frequency of K. pneumoniae isolates in different samples and units in hospitalized patients

\begin{tabular}{llllll}
\hline $\begin{array}{c}\text { Sample } \\
\text { Unite }\end{array}$ & Urine & Tracheal & Wound & Sputum & Blood \\
\hline ICU & $12(40 \%)$ & $10(55.6 \%)$ & $5(41.7 \%)$ & $3(33.3 \%)$ & $3(37.5 \%)$ \\
Surgery & $7(23.3 \%)$ & $4(22.2 \%)$ & $6(50 \%)$ & 0 & $1(12.5 \%)$ \\
Internal & $6(20 \%)$ & $4(22.2 \%)$ & $1(8.3 \%)$ & $6(66.7 \%)$ & $3(37.5 \%)$ \\
CCU & $5(16.7 \%)$ & 0 & 0 & 0 & $1(12.5 \%)$ \\
Total & $30(39 \%)$ & $18(23.3 \%)$ & $12(15.6 \%)$ & $9(11.7 \%)$ & $8(10.4 \%)$ \\
\hline
\end{tabular}




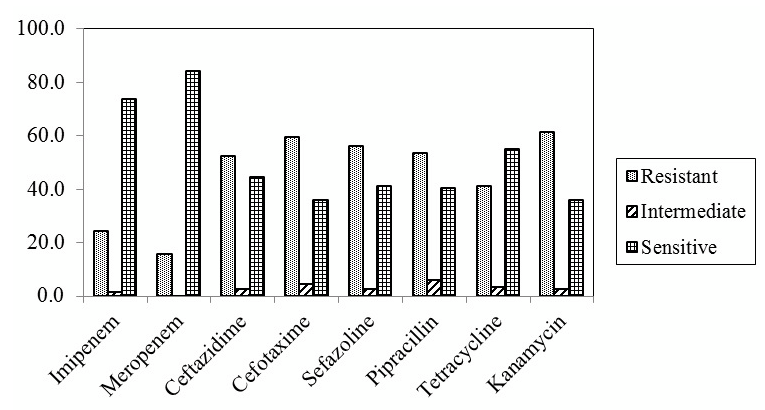

Fig. 1. Pattern of antibiotic use in K. pneumonia

Table 3. Antibiotic resistance of $K$. pneumoniae isolated from hospitalized patients and outpatients

\begin{tabular}{|c|c|c|c|}
\hline $\begin{array}{l}\text { Antibacterial } \\
\text { agents }\end{array}$ & $\begin{array}{l}\text { N } \\
(\mathrm{NO} \%)\end{array}$ & $\begin{array}{l}\text { Hospitalized } \\
\text { patients N } \\
(\mathrm{NO} \%)\end{array}$ & $\begin{array}{l}\text { Outpatients N } \\
\text { (NO\%) }\end{array}$ \\
\hline Imipenem & $28(24.6)$ & $22(28.5)$ & $6(7.8)$ \\
\hline Meropenem & $18(15.9)$ & $15(19.5)$ & $3(8.1)$ \\
\hline Cephotaxime & $68(59.6)$ & $49(63.8)$ & $19(51.4)$ \\
\hline Ceftazidime & $60(52.6)$ & $46(59.7)$ & $14(37.8)$ \\
\hline Cefazoline & $64(56.1)$ & $37(48)$ & $27(35)$ \\
\hline Pipraciline & $61(53.5)$ & $40(52)$ & $21(27.2)$ \\
\hline Tetracycline & $47(41.2)$ & $32(41.6)$ & $15(40.5)$ \\
\hline Kanamycin & $70(61.4)$ & $60(77.9)$ & $10(27)$ \\
\hline
\end{tabular}

for bla $a_{\mathrm{VIM}-2}$ gene.

Higher prevalence of VIM-1 producing isolates of $K$. pneumoniae was seen in urine samples (20\%). Only one VIM-1 producing $K$. pneumoniae isolates found in outpatient urine was detected by PCR. Distribution of metallo- $\beta$-lactamases in clinical samples are shown in Table 4.

\section{DISCUSSION}

K. pneumoniae is a member of the Enterobacteriaceae family. The quantity of reports shows that the isolation of species of this genus from both hospital and community samples has increased (17). In the current study, from total clinical samples, prevalence of $K$. pneumoniae was $28.5 \%$, which is close to the study in Brazil (26.2\%) (18), but it was higher in comparison with the study in Iran (25.3\%) (19), and a study in India (25\%) (20). In this study, $K$. pneumoniae showed varying levels ranging from

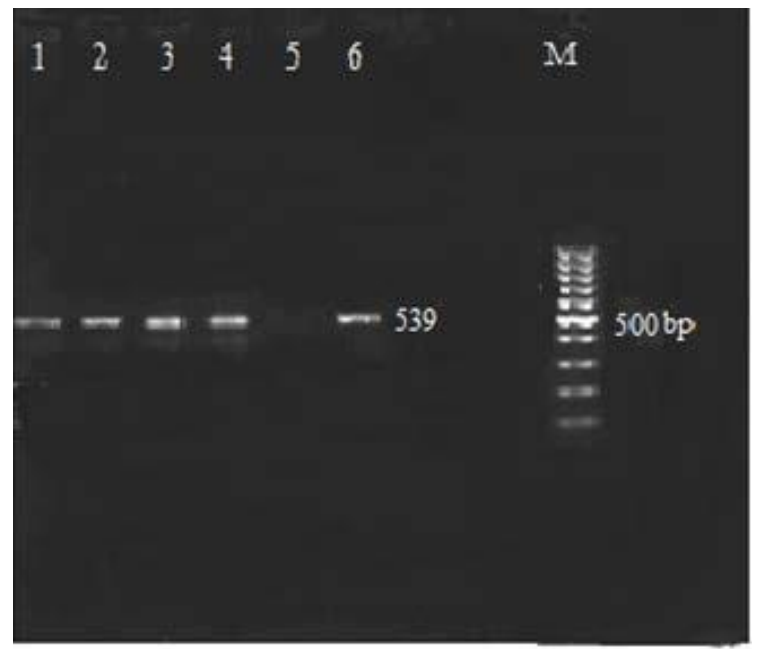

Fig. 2. PCR analysis for the $b l a_{\mathrm{VIM} 1}$ gene in $K$. pneumoniae lane 1, 2, 3, 4 have VIM1 gene; Lane 5 negative control (distilled water), lane 6 positive control $K$. pneumoniae ATCC 700603 and Lane M: DNA Ladder 100 bp

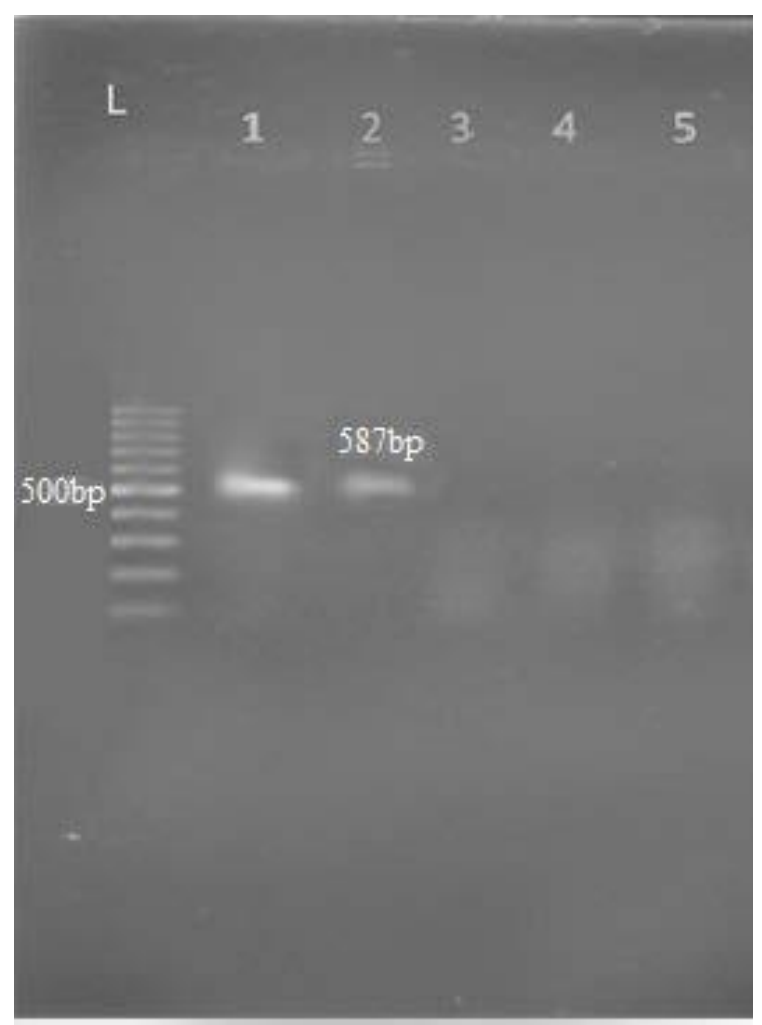

Fig. 3. PCR analysis for the $b l a_{\mathrm{IMP}}-1$ gene in K. pneumoniae Lane 1: positive control K. pneumoniae ATCC 700603, Lane 2: IMP-1gene Lane 3: Negative control (distilled water). Lane L: DNA Ladder $100 \mathrm{bp}$ 
Table 4. Distribution of K. pneumoniae MBLs production (VIM1, IMP1) in clinical samples

\begin{tabular}{lllllll}
\hline & Urine & Tracheal & Sputum & Blood & Wound & Total \\
\hline Metallo-3-Lactamase & $7(46.6 \%)$ & $4(26.7 \%)$ & $1(6.7 \%)$ & $1(6.7 \%)$ & $2(13.3 \%)$ & 15 \\
VIM-1 & $3(20 \%)$ & $1(6.7 \%)$ & 0 & 0 & 0 & 4 \\
IMP-1 & $1(6.7 \%)$ & 0 & 0 & 0 & 0 & 1 \\
\hline
\end{tabular}

susceptibility and resistance towards the tested antibiotics. Antibiotic resistance profiles of the isolates using disk diffusion method indicated that resistance to imipenem was $24.6 \%$ that was similar to Ghaffarian study (23.3\%) in 2018 (21) as well as Khodadadian $(25.6 \%)$ in 2018 (19), but it was lower than the finding of other studies conducted by Rajabnia (52\%) in 2015 (22) Lorenzoni (29.7\%) in 2018 (23). Our results proved that meropenem and imipenem remain effective drugs against $K$. pneumoniae isolates. In the present study, more than half of $K$. pneumoniae isolates were resistant to other important antimicrobial agents such as kanamycin $(61.4 \%)$, cefotaxime (59.6\%), cefazoline $(56.1 \%)$ and ceftazidime $(52.6 \%)$ which matched the results achieved in the north of Iran in 2016 (21).

Extensive variation in the prevalence and antibiotic resistance is probably due to the variation in risk factors, the widespread use of antibiotics for the treatment of infections and differences in geographical locations. Some of the important reasons for increasing drug resistance in Iran are the lack of communication between physicians and microbiologists, limited infection control programs and poor sanitation. The results of this study proved comparatively low resistance to the majority of $K$. pneumoniae isolates in the outpatients when compared to the patterns from hospitalized patients. These findings may imply that these drugs still be useful for treating uncomplicated cases where the organisms are indicated as etiologic agents of diseases in the hospital. In the present study, the highest number of K. pneumoniae were isolated from urine samples in hospitalized patients which admitted to ICU, and also maximum resistance to imipenem was observed in urine samples, which were accordance with studies of Rai in 2011 (17). ICU has been known as a source of creating, spreading and enhancing antimicrobial resistance and patients are exposed to a number of potential risk factors for colonization/infection such as high invasive procedures, elderly people, longterm hospitalization and misuse of suitable antibac- terial agents, and Klebsiella spp. is one of the most common pathogens isolated in ICUs (24).

In the past few years, MBLs have been identified via clinical isolating by increasing frequency. The enzymes produced by these strains ( $K$. pneumoniae) have been responsible for prolonged nosocomial outbreaks and a serious threat to public health worldwide (25).

In regards to MBL enzymes in this study (53.5\%) was in line with a study in India in 2012 (26), but it was higher compared to a study in Malaysia in 2015 (27). The results of this study showed that the majority of MBL producing $K$. pneumoniae (14/15) were extracted from hospitalized patients and only one isolate (1/15) was MBL producer in outpatients by DDST. The presence of MBL-producing bacteria in the outpatients portends serious health risk because the organisms that produce MBL are notably resistant to carbapenems including imipenem and meropenem, which are antibiotics reserved for serious bacterial infections (28). In this study, VIM-1 gene prevalence was $26.6 \%$ (4/15) which matched with the results achieved in India in 2013 (29), but it was higher than the study published in Iran in 2018 (19), and in India in 2014 (20), and it was lower compared to studies in Nepal 2014 (6). By DDST and PCR analysis, we determined one IMP-1 producing K. pneumoniae $(6.7 \%)$ in urine samples in hospitalized patients, which was similar to findings of Khodadadian study in 2018 (19), but it was lower than study reported by Jin Young in 2016 (30). It seems that the difference in the prevalence of MBL-producing $K$. pneumoniae strains in different hospitals is due to the genetic difference between species, spreads to resistance genes and affects the spread patterns of different MBLs in various countries.

In our study, the MICs (E-test) of imipenem against 4 VIM-1 and IMP-1 Metallo- $\beta$ lactamase producing $K$. pneumonaie isolates ranged from 4 to $32 \mathrm{mg} / \mathrm{l}$ and exhibited IPM resistant phenotypes. The resistance to imipenem may also be attributed to the loss of porins. In the present study, MBL positive 
isolates (5 strains) were resistant to at least 4 antibiotics including cefotaxime, cephazolin, ceftazidime, and kanamycin. In a study by Rastegar Lari et al. among $19 \mathrm{~K}$. pneumonaie isolates resistant to imipenem, 9 were resistant to all other antibiotics (2). Our data emphasizes the need to implement appropriate strategies to control the infection to detect MBL-producing strains in numerous hospitals, which can be an effective step to reduce the incidence of such as genes. In our study $b l a_{\mathrm{VIM}-1}$ and $b l a_{\mathrm{IMP}-1}$ were identified in $K$. pneumonaie isolates and studies have shown that other mechanisms of resistance may interfere in the MBL phenotypic detection. Thus, other carbapenemase producing genes should be investigated. The results of this study showed although the carbapenems had the best activity among the tested antibiotics, there is a high level of resistance in $K$. pneumoniae to most of the other tested antibiotics and the majority MBL production of K. pneumoniae was associated with hospitalized patients in ICU. Therefore, accurate and rapid detection of these MBL-producing strains is vital among isolates circulating in high-risk wards such as ICUs, for suitable selection of effective therapy and nosocomial infection control.

\section{ACKNOWLEDGEMENTS}

Author is grateful the Research Deputy and Microbiology Laboratory of Kurdistan University of Medical Science, Sanandaj, Iran.

\section{REFERENCES}

1. Maltezou HC, Giakkoupi P, Maragos A, Bolikas M, Raftopoulos V, Papahatzaki H, et al. Outbreak of infections due to KPC-2-producing Klebsiella pneumoniae in a hospital in Crete (Greece). J Infect 2009; 58:213219.

2. Rastegar Lari A, Azimi L, Rahbar M, Fallah F, Alaghehbandan R. Phenotypic detection of Klebsiella pneumoniae carbapenemase among burns patients: First report from Iran. Burns 2013; 39:174-176.

3. Bush K, Jacoby GA. Updated functional classification of B-lactamases. Antimicrob Agents Chemother 2010; 54:969-976.

4. Ambler RP. The structure of beta-lactamases. Philos Trans R Soc Lond B Biol Sci 1980; 289: 321-331.
5. Lee K, Ha GY, Shin BM, Kim JJ, Kang JO, Jang SJ, et al. Metallo- $\beta$-lactamase-producing Gram-negative bacilli in Korean nationwide surveillance of antimicrobial resistance group hospitals in 2003: Continued prevalence of VIM-producing pseudomonas spp. and increase of IMP-producing Acinetobacter spp. Diagn Microbiol Infect Dis 2004; 50:51-58.

6. Bora A, Sanjana R, Jha BK, Mahaseth SN, Pokharel K. Incidence of metallo-beta-lactamase producing clinical isolates of Escherichia coli and Klebsiella pneumoniae in central Nepal. BMC Res Notes 2014; 7:557.

7. Luzzaro F, Endimiani A, Docquier JD, Mugnaioli C, Bonsignori $\mathrm{M}$, Amicosante $\mathrm{G}$, et al. Prevalence and characterization of metallo- $\beta$-lactamases in clinical isolates of Pseudomonas aeruginosa. Diagn Microbiol Infect Dis 2004; 48: 131-135.

8. Japoni-Nejad A, Ghaznavi-Rad E, van Belkum A. Characterization of plasmid-mediated AmpC and Carbapenemases among Iranain nosocomial isolates of Klebsiella pneumoniae using phenotyping and genotyping methods. Osong Public Health Res Perspect 2014; 5: 333-338.

9. Lee K, Chong Y, Shin H B, Kim Y A, Yong D, Yum JH. Modified hodge and EDTA-disk synergy tests to screen metallo-beta-lactamase-producing strains of Pseudomonas and Acinetobacter species. Clin Microbiol Infect 2001; 7: 88-91.

10. Walsh TR, Bolmstrom A, Qwarnstrom A, Gales A. Evaluation of a new E-test for detecting metallo- $\beta$-lactamases in routine clinical testing. J Clin Microbiol 2002; 40:2755-2759.

11. Senda K, Arakawa Y, Ichiyama S, Nakashima K, Ito H, Ohsuka S, et al. PCR detection of metallo-lactamase gene $b l a_{\mathrm{IMP}}$ gram-negative rods resistant to broad-spectrum Blactams. J Clin Microbiol 1996; 34: 2909-2913.

12. Isenberg HD. Clinical microbiology: past, present, and future. J Clin Microbiol 2003; 41:917-918.

13. Clinical and laboratory standards institute. Performance standards for antimicrobial susceptibility testing twenty-fourth informational supplement document. Wayne Pu Publication.2014; P.100-24.

14. Chandrasekaran S, Abbott A, Campeau S, Zimmer BL, Weinstein M, Thrupp L, et al. Direct-from-blood-culture disk diffusion to determine antimicrobial susceptibility of Gram-negative bacteria: preliminary report from the clinical and laboratory standards institute methods development and standardization working group. J Clin Microbiol 2018; 56(3): e01678-17.

15. Sung K, Khan SA, Nawaz MS, Khan AA. A simple and efficient Triton X-100 boiling and chloroform extraction method of RNA isolation from Gram-positive and Gram-negative bacteria. FEMS Microbiol Lett 2003; 229:97-101.

16. Salimi F, Eftekhar F. Prevalence of $b l a_{\mathrm{IMP}}$, and $b l a_{\mathrm{VIM}}$ 
gene carriage in metallo- $\beta$-lactamase-producing burn isolates of Pseudomonas aeruginosa in Tehran. Turk $J$ Med Sci 2014; 44:511-514.

17. Rai S, Manchanda V, Singh NP, Kaur IR. Zinc-dependent carbapenemases in clinical isolates of family Enterobacteriaceae. Indian J Med Microbiol 2011; 29: 275-279.

18. Sampaio JL, Gales AC. Antimicrobial resistance in Enterobacteriaceae in Brazil: focus on $\beta$-lactams and polymyxins. Braz J Microbiol 2016; 47(Suppl 1): 31-37.

19. Khodadadian R, Rahdar H A, Javadi A, Mahmod S, Khorshidi A. Detection of VIM-1 and IMP-1 genes in Klebsiella pneumoniae and relationship with biofilm formation. Microb Pathog 2018; 115: 25-30.

20. Shashwati N, Kiran T, Dhanvijay AG. Study of extended spectrum $\beta$-lactamase producing Enterobaceriace$a e$ and antibiotic co-resistance in a tertiary care teaching hospital. J Nat Sci Biol Med 2014; 5: 30-35.

21. Ghaffarian F, Hedayati M, Sedigh Ebrahim-Saraie H, Atrkar Roushan Z, Mojtahedi A. Molecular epidemiology of ESBL-producing Klebsiella pneumoniae isolates in intensive care units of a tertiary care hospital, north of Iran. Cell Mol Biol (Noisy-le-grand) 2018; 64:75-79.

22. Rajabnia R, Asgharpour F, Ferdosi E, Moulana Z. Nosocomial emerging of (VIM1) carbapenemase-producing isolates of Klebsiella pneumoniae in north of Iran. Iran J Microbiol 2015; 7:88-93.

23. Lorenzoni VV, Rubert FDC, Rampelotto RF, Hörner R. Increased antimicrobial resistance in Klebsiella pneumoniae from a University Hospital in Rio Grande do Sul, Brazil. Rev Soc Bras Med Trop 2018; 51:676-679.

24. Brusselaers N, Vogelaers D, Blot S. The rising problem of antimicrobial resistance in the intensive care unit. Ann Intensive Care 2011; 1:47.

25. I-Ling T, Yu-Mei L, Shiow-Jen W, Hung-Yi Y, ChiaLun H, Hsueh-Lin, et al. Emergence of carbapenemase producing Klebsiella pneumonia and spread of KPC-2 and KPC-17 in Taiwan: A nationwide study from 2011 to 2013. PLoS One 2015; 10(9):e0138471.

26. Datta P, Gupta V, Garg S, Chander J. Phenotypic method for differentiation of carbapenemases in Enterobacteriaceae: Study from north India. Indian J Pathol Microbiol 2012: 55:357-360.

27. Hamzan NI, Yean CY, Rahman RA, Hasan H, Rahman ZA. Detection of $b l a_{\mathrm{IMP} 4}$ and $b l a_{\mathrm{NDM} 1}$ harboring Klebsiella pneumoniae isolates in a university hospital in Malaysia. Emerg Health Threats J 2015; 8: 26011.

28. Ikegbunam MN, Anagu LO, Iroha IR, Ejikeugwu CE, Esimone CO. Abattoirs as non-hospital source of extended spectrum beta lactamase producers: confirmed by the double disc synergy test and characterized by matrix-assisted laser desorption/ionization time of flight mass spectrometry. PLoS One 2014; 9(4):e94461.

29. Lascols C, Peirano G, Hackel M, Laupland K B, Pitout J D. Surveillance and molecular epidemiology of Klebsiella pneumoniae that produce carbapenemases; the first report of OXA-48-like enzymes in North America. Antimicrob Agents Chemother 2013; 57:130136.

30. Jin Young L, Ji Young P, Je Hun K, Young H L, Hee Young Y, Jung Sik Y. Outbreak of Imipenemase-1-producing carbapenem-resistant Klebsiella pneumoniae in an intensive care unit. Korean J Crit Care Med 2017; 32:29-38. 